\title{
Smokeless tobacco use: its prevalence and relationships with dental symptoms, nutritional status and blood pressure among rural women in Burkina Faso
}

Jeoffray Diendéré ${ }^{1,2^{*}}$, Augustin Nawidimbasba Zeba ${ }^{1}$, Léon Nikièma ${ }^{3}$, Ahmed Kaboré ${ }^{2,3}$, Paul Windinpsidi Savadogo ${ }^{4}$, Somnoma Jean-Baptiste Tougma ${ }^{5}$, Halidou Tinto ${ }^{2,6}$ and Arouna Ouédraogo ${ }^{7}$

\begin{abstract}
Background: Sub-Saharan women use smokeless tobacco (SLT) more than smoked tobacco. Among Western African countries, the estimated weighted prevalence of SLT use in rural women was found to be the highest in Burkina Faso (after Sierra Leone). This study aimed to assess the prevalence of SLT use and its associated factors among rural women in Burkina Faso by using nationally representative data.

Methods: We used data from the 2013 STEPwise approach to Surveillance (STEPS) study, which provided sociodemographic, clinical (anthropometric, systolic blood pressure [SBP], diastolic blood pressure [DBP] and dental symptoms), biological (total and high-density lipoprotein cholesterol and fasting blood sugar), and tobacco and alcohol consumption data. Data for 1730 rural women were used, and we performed Student's chi-squared and logistic regression analyses.

Results: The prevalence of current SLT use was 13.8\% (95\% Cl: 12.2-15.5). Significant risks for SLT use were the presence of dental symptoms (adjusted odds ratio $[\mathrm{aOR}]=2.59 ; p<0.001)$, undernourishment $(\mathrm{aOR}=1.78 ; p<0.01)$, decreased waist circumference $(\mathrm{aOR}=0.98 ; p<0.05)$, decreased DBP $(\mathrm{aOR}=0.97 ; p<0.01)$, increased $\mathrm{SBP}(\mathrm{aOR}=$ $1.01 ; p<0.05)$, and increased differential blood pressure ( $\mathrm{aOR}=1.01 ; p<0.05)$. The co-use of alcohol was also a significant risk factor $(\mathrm{aOR}=2.80 ; p<0.001)$.

Conclusion: The prevalence of current SLT use was high among rural women in Burkina Faso, and significant concerns for users included alcohol co-use, the occurrence of dental symptoms, undernourishment, and an increase in differential blood pressure. National Public Health interventions are needed to reduce SLT use and its healthrelated concerns.
\end{abstract}

Keywords: Smokeless tobacco, Alcohol co-use, Dental symptoms, Undernourishment, Blood pressure, Rural women, Burkina Faso

\footnotetext{
* Correspondence: jeoffray.diendere@gmail.com

${ }^{1}$ Public Health Department, Research Institute for Health Sciences, 399,

Avenue de la Liberté, 01 BP 545, Bobo-Dioulasso 01, Burkina Faso

${ }^{2}$ Public Health Department, Centre Muraz, Bobo-Dioulasso, Burkina Faso

Full list of author information is available at the end of the article
}

C C The Author(s). 2020 Open Access This article is licensed under a Creative Commons Attribution 4.0 International License, which permits use, sharing, adaptation, distribution and reproduction in any medium or format, as long as you give appropriate credit to the original author(s) and the source, provide a link to the Creative Commons licence, and indicate if changes were made. The images or other third party material in this article are included in the article's Creative Commons licence, unless indicated otherwise in a credit line to the material. If material is not included in the article's Creative Commons licence and your intended use is not permitted by statutory regulation or exceeds the permitted use, you will need to obtain permission directly from the copyright holder. To view a copy of this licence, visit http://creativecommons.org/licenses/by/4.0/. The Creative Commons Public Domain Dedication waiver (http://creativecommons.org/publicdomain/zero/1.0/) applies to the data made available in this article, unless otherwise stated in a credit line to the data. 


\section{Background}

Smokeless tobacco (SLT) and smoked tobacco (ST) are both used in sub-Saharan African (SSA) countries, and SLT is used more than twice as often in rural areas than in urban areas [1]. The prevalence of SLT use in women is more than three times higher in rural areas than in urban areas [1]. In SSA countries, the most favoured form of tobacco for females is SLT, mostly used orally in a chewable form $[2,3]$. In Qatar, women have impaired oral health approximately twice as frequently as men do, and SLT use is approximately four times higher when people have impaired oral health [4], which is sometimes considered to be a motivation for using SLT. The level of awareness of the health risks associated with the consumption of SLT products is low, particularly among people with low socioeconomic status or those in rural areas [5]. The sociocultural environment is an important influencing factor in the initiation of SLT use [6]. In a report on 10 West African countries between 2008 and 2012, the weighted prevalence estimate of SLT use in rural women was highest in Burkina Faso (after Sierra Leone), and more than $80 \%$ of the women were reported to use chewing tobacco [1]. Compared to the use of ST, the use of SLT (especially chewing tobacco) by females is not socially stigmatizing in Burkina Faso. The harmfulness of SLT appears to be misunderstood, and traditionally, symbolic gifts (from urban residents) to elders in rural areas often include tobacco products. National Public Health interventions regarding tobacco use exclusively target ST consumption, devoting only limited attention to other types of products, including SLT. However, the toxicity, mutagenicity, and carcinogenic effects of the hazardous chemicals present in SLT products have been documented [7]. Similar to ST, SLT includes nicotine as the primary psychoactive and addictive molecule, and the systemic absorption and nicotine levels were similar in SLT users and cigarette smokers [8]. In addition, depending on the cultivated soils and production processes, some unusually high levels of known components and unexpected toxins have been identified in SLT leaves [9, 10]. Recent international studies revealed serious health concerns related to SLT consumption, specifically oral health impairment $[11,12]$, nutritional disorders [13], co-use of psychoactive substances, and cardiovascular disease [14-16]. In Burkina Faso, no previous study using a representative sample has reported the national prevalence of SLT use and its health-related consequences in rural areas, particularly among females. The first national survey using the World Health Organization (WHO) standardized STEPwise approach to Surveillance (STEPS) [17] also provided data on tobacco consumption. Our study aimed to assess the prevalence of SLT use and its relationships with dental symptoms, nutritional status, and blood pressure level among rural women in Burkina Faso using nationally representative data.

\section{Methods}

We used data from the first Burkina Faso national survey conducted in 2013, which was based on the WHO STEPS methodology [17]. The protocol of the STEPS survey was approved by the Ethics Committee for Health Research of the Ministry of Health of Burkina Faso (deliberation No: 2012-12092; December 05, 2012). Written informed consent was systematically obtained from each participant in the STEPS survey. The sample calculation and data collection methods have been described [18, 19]. The number of surveyed rural women was 1920 and we reanalysed variables for those with complete data for the sociodemographic, lifestyle, nutritional and biological parameters and with responses to items that screened dental symptoms. Thus, we included 1730 women in the analyses, and Fig. 1 presents the diagram flow of the women we studied.

\section{Variables of interest}

Participants' demographic variables included age, marital status, education level, and occupation. We also reported whether the women were living in households with at least one member aged $\geq 18$ years. The anthropometric characteristics were weight $(\mathrm{kg})$, height $(\mathrm{m})$, body mass index $\left(\mathrm{BMI}=\right.$ weight $/ \mathrm{height}^{2}$, in $\mathrm{kg} / \mathrm{m}^{2} ;$ a $\mathrm{BMI}<18.5 \mathrm{~kg} /$ $\mathrm{m}^{2}$ was considered underweight, a BMI of $18.5-24.9 \mathrm{~kg} /$ $\mathrm{m}^{2}$ was considered normal weight, and a BMI $\geq 25 \mathrm{~kg} /$ $\mathrm{m}^{2}$ was considered overweight/obese) and waist circumference $(\mathrm{cm})$. The biological characteristics tested in blood were total cholesterol ( $\mathrm{mmol} / \mathrm{l})$, high-density lipoprotein cholesterol (HDL, in $\mathrm{mmol} / \mathrm{l}$ ), and fasting sugar (mmol/l). Blood pressure (in $\mathrm{mmHg}$, which included systolic blood pressure [SBP] and diastolic blood pressure [DBP] values) was measured three times, and we kept only the mean value for each indicator; levels $\geq 140 / 90$ $\mathrm{mmHg}$ defined high blood pressure (HBP), and the difference between the mean values of SBP and DBP (SBP - DBP) was used to determine the differential blood pressure. Lifestyle factors were determined by using selfreporting techniques and included current (past month) alcohol consumption and current (past year) smokeless (chewing, snorting) or smoked tobacco consumption. Dental problems were also recorded by using a selfreported method to report having the following during the past 12 months: i) difficulties chewing food, ii) difficulties with speech/trouble pronouncing word or iii) pain or discomfort in the teeth/mouth.

\section{Statistical analyses}

We used StataCorp Stata Statistical Software for Windows (Version 12.0, College Station, Texas, US) to 


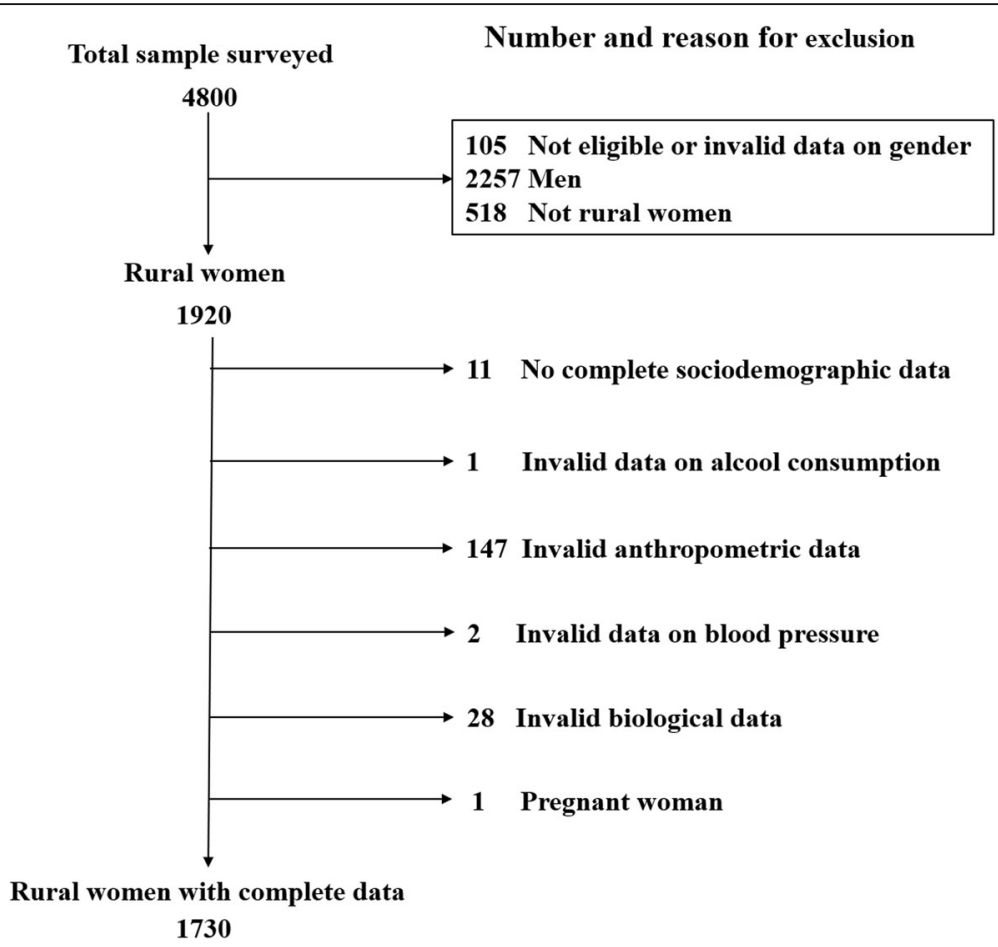

Fig. 1 Flow diagram of the women included in the analyses

Table 1 Sociodemographic characteristics for all rural women $(n=1730)$

\begin{tabular}{|c|c|c|c|c|c|c|c|}
\hline & \multicolumn{2}{|c|}{$\begin{array}{l}\text { Overall } \\
n=1730\end{array}$} & \multicolumn{2}{|c|}{$\begin{array}{l}\text { Not users of smokeless } \\
\text { tobacco } \\
n=1492\end{array}$} & \multicolumn{2}{|c|}{$\begin{array}{l}\text { Users of smokeless } \\
\text { tobacco } \\
n=238\end{array}$} & \multirow[b]{2}{*}{$p$ value } \\
\hline & $n$ & $\%(95 \% \mathrm{Cl})$ & $n$ & $\%(95 \% \mathrm{Cl})$ & $n$ & $\%(95 \% \mathrm{Cl})$ & \\
\hline Age mean \pm standard deviation (years) & 1730 & $37.8 \pm 10.9$ & & $36.7 \pm 10.5$ & & $44.6 \pm 11.0$ & $* * *$ \\
\hline Age range (years) & & & & & & & *** \\
\hline$-25-34$ & 809 & $46.8(44.4-49.1)$ & 757 & $50.7(48.2-53.3)$ & 52 & $21.8(16.8-27.6)$ & \\
\hline$-35-49$ & 592 & $34.2(32.0-36.5)$ & 503 & $33.7(31.3-36.2)$ & 89 & $37.4(31.2-43.9)$ & \\
\hline$->49$ & 329 & $19.0(17.2-20.9)$ & 232 & $15.6(13.7-17.5)$ & 97 & $40.8(34.5-47.3)$ & \\
\hline Marital status & & & & & & & $* * *$ \\
\hline - Married/cohabitating & 1553 & $89.8(88.2-91.2)$ & 1357 & $91.0(89.4-92.4)$ & 196 & $82.4(76.9-87.0)$ & \\
\hline - Singles & 177 & $10.2(8.8-11.8)$ & 135 & $9.0(7.6-10.6)$ & 42 & $17.6(13.0-23.1)$ & \\
\hline Education level & & & & & & & $* * *$ \\
\hline - No formal education & 1558 & $90.1(88.6-91.4)$ & 1326 & $88.9(87.2-90.4)$ & 232 & $97.5(94.6-99.1)$ & \\
\hline - Primary school or more & 172 & $9.9(8.6-11.4)$ & 166 & $11.1(9.6-12.8)$ & 6 & $2.5(0.9-5.4)$ & \\
\hline Occupation & & & & & & & NS \\
\hline - Employed/Self-employed & 1002 & $57.9(55.6-60.3)$ & 866 & $58.0(55.5-60.6)$ & 136 & $57.1(50.6-63.5)$ & \\
\hline - Others (Students+household-keepers+unemployed) & 728 & $42.1(39.7-44.4)$ & 626 & $42.0(39.4-44.5)$ & 102 & $42.9(36.5-49.4)$ & \\
\hline Having at least one family member aged $\geq 18$ years, yes & 1286 & $74.3(72.2-76.4)$ & 1118 & $74.9(72.7-77.1)$ & 168 & $70.6(64.4-76.3)$ & NS \\
\hline Current alcohol use, yes & 425 & $24.6(22.6-26.7)$ & 316 & $21.2(19.1-23.3)$ & 109 & $45.8(39.3-52.4)$ & $* * *$ \\
\hline Presence of dental symptom, yes & 417 & $24.1(22.1-26.2)$ & 312 & $20.9(18.9-23.1)$ & 105 & $44.1(37.7-50.7)$ & *** \\
\hline
\end{tabular}

NS indicates Non-Significant $p$ value; *** indicates $p$ value $<0.001$

Only one woman used the ST (>0.0\%; $95 \% \mathrm{Cl}:>0.0-0.03)$ 
analyse the data. The quantitative variables were expressed as the means \pm standard deviations, and the categorical variables were expressed as percentages (\%), with a confidence interval of $95 \%$ (95\%, CI). Student's ttest was used to compare quantitative variables, and the chi-squared test was used for categorical variables. Logistic regression analysis was performed to identify the clinical, biological, and lifestyle factors associated with SLT after adjusting for sociodemographic features. The model was determined by backward elimination (i.e., the progressive elimination of nonsignificant factors by decreasing order of significance). For all analyses, a $p$-value below 0.05 was considered significant.

\section{Results}

The mean age in the sample was $37.8 \pm 10.9$ years, and other sociodemographic characteristics are presented in Table 1 . Only one woman used ST $(>0.0 \%)$. The prevalence of SLT use was $13.8 \%$ (95\% CI: 12.2-15.5), the prevalence of current alcohol use was 24.6\% (95\% CI: 22.6-26.7), the prevalence of dental symptoms was $24.1 \%$ (95\%; CI: 22.1-26.2), the prevalence of undernourishment was $16.0 \%$ (95\%; CI: 14.3-17.8), and the prevalence of HBP was $14.6 \%$ (95\%; CI: $13.0-16.4)$. The means of all anthropometric parameters for SLT users were significantly lower than those for nonusers: $53.2 \pm$ $9.0 \mathrm{~kg}$ vs $56.9 \pm 10.3$ for weight, $20.2 \pm 3.1 \mathrm{~kg} / \mathrm{m}^{2}$ vs $21.7 \pm 3.6$ for BMI and $74.6 \pm 10.7 \mathrm{~cm}$ vs $76.4 \pm 11.7$ for waist circumference (each $p$-value $<0.05$ ), respectively. The mean SBP was significantly higher in SLT users than in nonusers $(122.9 \pm 19.8 \mathrm{mmHg}$ vs $119.6 \pm 16.1$; $p<0.01)$, as was the differential blood pressure $(46.3 \pm$ $13.9 \mathrm{mmHg}$ vs $42.8 \pm 11.3 ; p<0.001)$. However, there was no significant difference in the mean DBP between SLT users and nonusers $(76.6 \pm 10.3 \mathrm{mmHg}$ vs. $76.8 \pm$ $10.0 ; p=0.72)$. The mean glycaemia was also higher for SLT users $(4.1 \pm 1.5 \mathrm{mmol} / \mathrm{l}$ vs. $3.8 \pm 1.5$ for nonusers, $p<0.05$; Table 2).

The results of the logistic regression are reported in Table 3. Significant risks associated with SLT use were the co-use of alcohol (adjusted odds ratio $[\mathrm{aOR}]=2.80$; 95\% CI: 2.06-3.80), the presence of dental symptoms $(\mathrm{aOR}=2.59 ; \quad 95 \% \quad \mathrm{CI}:$ 1.91-3.51), undernourishment $(\mathrm{aOR}=1.78 ; 95 \% \mathrm{CI}: 1.24-2.55)$, a decreased waist circumference $(\mathrm{aOR}=0.98 ; 95 \%$ CI: $0.97-<1.00 ; p<0.05)$, decreased DBP (aOR $=0.97$; 95\% CI: $0.95-0.99)$ and increased SBP $(\mathrm{aOR}=1.01 ; 95 \% \mathrm{CI}:>1.00-1.03 ; p<0.05)$. When replacing both the SBP and DBP variables with the single differential blood pressure (SBP-DBP in $\mathrm{mmHg}$ ) in the multivariable model, the differential unit

Table 2 Nutritional, clinical, and biological features of rural women according to the use of psychoactive substances ( $n=1730$ )

\begin{tabular}{|c|c|c|c|c|c|c|c|}
\hline \multirow[t]{3}{*}{ Parameters } & \multicolumn{7}{|c|}{ Mean \pm standard deviation or $\%$ ( $95 \%$ confident interval) } \\
\hline & \multirow{2}{*}{$\begin{array}{l}\text { Overall } \\
(n=1730)\end{array}$} & \multirow{2}{*}{$\begin{array}{l}\text { Current SLT } \\
\text { users } \\
(n=238)\end{array}$} & \multirow{2}{*}{$\begin{array}{l}\text { Not current SLT } \\
\text { users } \\
(n=1492)\end{array}$} & \multirow[t]{2}{*}{$\begin{array}{l}p \\
\text { value }\end{array}$} & \multirow{2}{*}{$\begin{array}{l}\text { Current SLT and } \\
\text { alcohol users } \\
(n=109)\end{array}$} & \multirow{2}{*}{$\begin{array}{l}\text { Current SLT and not } \\
\text { alcohol users } \\
(n=1621)\end{array}$} & \multirow[t]{2}{*}{$\begin{array}{l}p \\
\text { value }\end{array}$} \\
\hline & & & & & & & \\
\hline Waist circumference,(cm) & $76.2 \pm 11.6$ & $74.6 \pm 10.7$ & $76.4 \pm 11.7$ & * & $75.0 \pm 11.8$ & $76.3 \pm 11.6$ & NS \\
\hline Weight,(kg) & $56.4 \pm 10.2$ & $53.2 \pm 9.0$ & $56.9 \pm 10.3$ & $* * *$ & $52.7 \pm 8.1$ & $56.7 \pm 10.3$ & $* * *$ \\
\hline Body mass index, $\left(\mathrm{kg} / \mathrm{m}^{2}\right)$ & $21.5 \pm 3.6$ & $20.2 \pm 3.1$ & $21.7 \pm 3.6$ & $* * *$ & $20.2 \pm 2.8$ & $21.6 \pm 3.6$ & $* * *$ \\
\hline \multicolumn{8}{|l|}{ Nutritional state } \\
\hline - Underweight & $\begin{array}{l}16.0(14.3- \\
17.8)\end{array}$ & $\begin{array}{l}28.6(22.9- \\
34.8)\end{array}$ & $13.9(12.2-15.8)$ & $* * *$ & $28.4(20.2-37.9)$ & $15.1(13.4-17.0)$ & ** \\
\hline - Normal & $\begin{array}{l}70.9(68.7- \\
73.1)\end{array}$ & $\begin{array}{l}66.0(59.6- \\
72.0)\end{array}$ & $71.7(69.4-74.0)$ & NS & $66.1(56.4-74.9)$ & $71.3(69.0-73.4)$ & NS \\
\hline - Overweight/obesity & $\begin{array}{l}13.1(11.6- \\
14.8)\end{array}$ & $5.5(2.9-9.2)$ & $14.4(12.6-16.2)$ & $* * *$ & $5.5(2.0-11.6)$ & $13.6(12.0-15.4)$ & $* * *$ \\
\hline Systolic blood pressure (mmHg) & $120.0 \pm 16.7$ & $122.9 \pm 19.8$ & $119.6 \pm 16.1$ & $* *$ & $119.9 \pm 16.3$ & $120.1 \pm 16.7$ & NS \\
\hline Diastolic blood pressure (mmHg) & $76.8 \pm 10.0$ & $76.6 \pm 10.3$ & $76.8 \pm 10.0$ & NS & $76.3 \pm 9.8$ & $76.8 \pm 10.05$ & NS \\
\hline $\begin{array}{l}\text { Differential blood pressure } \\
(\mathrm{mmHg})\end{array}$ & $43.3 \pm 11.8$ & $46.3 \pm 13.9$ & $42.8 \pm 11.3$ & $* * *$ & $43.6 \pm 11.3$ & $43.2 \pm 11.8$ & NS \\
\hline $\begin{array}{l}\text { High blood pressure, yes (> 140/ } \\
90 \mathrm{mmHg} \text { ) }\end{array}$ & $\begin{array}{l}14.6(13.0- \\
16.4)\end{array}$ & $\begin{array}{l}16.4(11.9- \\
21.7)\end{array}$ & $14.3(12.6-16.2)$ & NS & $13.8(7.9-21.7)$ & $14.7(13.0-16.5)$ & NS \\
\hline Blood sugar(mmol/l) & $3.9 \pm 1.5$ & $4.1 \pm 1.5$ & $3.8 \pm 1.5$ & * & $4.2 \pm 1.4$ & $3.9 \pm 1.5$ & * \\
\hline $\begin{array}{l}\text { Hyperglycemia, yes (> } 6.1 \mathrm{mmol} / \\
\text { I) }\end{array}$ & $5.0(4.0-6.1)$ & $5.5(2.9-9.2)$ & $4.9(3.9-6.1)$ & NS & $5.5(2.0-11.6)$ & $4.6(3.6-5.7)$ & NS \\
\hline HDL cholesterol,(mmo/l) & $0.9(0.5)$ & $0.9 \pm 0.4$ & $0.9 \pm 0.5$ & NS & $1.0 \pm 0.5$ & $0.9 \pm 0.5$ & NS \\
\hline Total cholesterol,(mmol/l) & $3.1(0.8)$ & $3.1 \pm 0.8$ & $3.1 \pm 0.8$ & NS & $3.2 \pm 1.0$ & $3.0 \pm 0.8$ & $*$ \\
\hline
\end{tabular}

NS indicates Non-Significant $p$ value; ${ }^{*}$ indicates $p$ value $<0.05 ;{ }^{* *}$ indicates $p$ value $<0.01 ;{ }^{* *}$ indicates $p$ value $<0.001$ 
Table 3 Factors associated with smokeless tobacco use among rural women in Burkina Faso $(n=1730)$

\begin{tabular}{|c|c|c|c|c|c|c|}
\hline \multirow[t]{2}{*}{ Factors } & \multicolumn{3}{|c|}{ Univariate analysis } & \multicolumn{3}{|c|}{ Multivariate analysis } \\
\hline & $\mathrm{COR}$ & $95 \% \mathrm{Cl}$ & $p$ value & $\mathrm{aOR}$ & $95 \% \mathrm{Cl}$ & $\boldsymbol{p}$ value \\
\hline \multicolumn{7}{|l|}{ Age range (years) } \\
\hline$-25-34$ & 1 & & & & & \\
\hline$-35-49$ & 1.58 & $1.80-3.69$ & $* * *$ & 2.14 & $1.46-3.13$ & $* * *$ \\
\hline$->49$ & 6.09 & $4.21-8.79$ & $* * *$ & 4.31 & $2.86-6.48$ & $* * *$ \\
\hline Occupation: others\#, vs employed/self-employed & 1.04 & $0.79-1.37$ & NS & 0.97 & $0.71-1.32$ & NS \\
\hline Marital status: Singles vs married/cohabiting (ref) & 2.15 & $1.48-3.14$ & $* * *$ & 1.12 & $0.73-1.74$ & NS \\
\hline Having at least one family member aged $\geq 18$ years: No, vs yes (ref) & 1.25 & $0.92-1.69$ & NS & 0.89 & $0.61-1.26$ & NS \\
\hline *Education level: no education or primary school vs secondary or more (ref) & 4.84 & $2.12-11.06$ & $* * *$ & 3.02 & $1.28-7.10$ & * \\
\hline Current alcohol use: yes, vs no (ref.) & 3.14 & $2.37-4.18$ & *** & 2.80 & $2.06-3.80$ & $* * *$ \\
\hline Presence of dental symptom: yes, vs no (ref) & 2.99 & $2.25-3.97$ & $* * *$ & 2.59 & $1.91-3.51$ & $* * *$ \\
\hline Waist circumference (cm) & 0.98 & $0.97-0.99$ & * & 0.98 & $0.97-<1.00$ & * \\
\hline Undernourishment (BMl $\left.<18.5 \mathrm{~kg} / \mathrm{m}^{2}\right)$ : yes, vs no (ref) & 2.47 & $1.80-3.39$ & $* * *$ & 1.78 & $1.24-2.55$ & ** \\
\hline Systolic blood pressure $(\mathrm{mmHg})$ & 1.01 & $>1.00-1.02$ & ** & 1.01 & $>1.00-1.03$ & * \\
\hline Diastolic blood pressure (mmHg) & $>0.99$ & $0.98-1.01$ & NS & 0.97 & $0.95-0.99$ & ** \\
\hline Blood sugar (mmol/L) & 1.10 & $1.01-1.20$ & * & 1.06 & $0.96-1.18$ & NS \\
\hline HDL cholesterol (mmol/l) & 1.08 & $0.81-1.43$ & NS & 0.90 & $0.64-1.25$ & NS \\
\hline Total cholesterol (mmol/L) & 1.05 & $0.88-1.24$ & NS & 0.97 & $0.78-1.21$ & NS \\
\hline
\end{tabular}

NS indicates Non-Significant $p$ value; * indicates $p$ value $<0.05 ;{ }^{* *}$ indicates $p$ value $<0.01$; ** indicates $p$ value $<0.001$

cOR crude odds ratio, $a O R$ adjusted odds ratio, $95 \%$ Cl $95 \%$ confidence interval, others\#: included professions with inconstant incomes (students, homemakers, and the unemployed). In this multivariate model, by replacing the dichotomic variable "undernourishment: yes or no" with the quantitative variable "BMI in kg/ $\mathrm{m}^{2 \prime \prime}$ and the two quantitative variables SBP and DBP with the differential blood pressure (SBP-DBP in mmHg), we observed that the decrease in the unit of BMI $(\mathrm{aOR}=0.88 ; 95 \% \mathrm{Cl}: 0.83-0.93 ; p<0.001)$ or the increase in the unit of differential blood pressure $(\mathrm{aOR}=1.01 ; 95 \% \mathrm{Cl}$ : $>1.00-1.02 ; p<0.05)$ were significantly associated with SLT use

increase was also significant $(\mathrm{aOR}=1.01 ; 95 \% \mathrm{CI}$ : > $1.00-1.02 ; \quad p<0.05)$. Concerning sociodemographic variables, significant risk factors were old age (with the 25-34-year-old subgroup as the reference; aOR $=2.14$; 95\% CI: $1.46-3.13$ in the 35-49-year-old subgroup; $\mathrm{aOR}=4.31$; $95 \% \mathrm{CI}: 2.86-6.48$ in the $>49$-year-old subgroup) and lack of education (with the group with a secondary education level as the reference; $\mathrm{aOR}=3.02$; $95 \%$ CI: 1.28-7.10).

\section{Discussion}

The prevalence of current SLT use was high among rural women in Burkina Faso, and given the current state of epidemiologic transition, the relationship of SLT use with noncommunicable diseases should make SLT use a public health concern.

\section{Prevalence of SLT use}

The prevalence of current SLT use among rural women in Burkina Faso was 13.8\% (95\% CI: 12.2-15.5), while only one woman used ST. Such statistics suggest a socially permissive attitude towards SLT use by females. A lower standardized prevalence estimate of $3.86 \%$ (95\% CI: 3.22-4.48) was noted 2 years earlier (in 2011 and only in the sample of women aged 15-49 years) [1]. A current prevalence of SLT use of 17.4\% (95\% CI: $14.5-$ 20.5) was found in rural women in three Ethiopian pastoral communities in which SLT chewing was a longstanding tradition [6], and the current prevalence of SLT use was $10.1 \%$ (95\% CI: 8.8-11.4) in Mozambique [20]. Studies focusing on female SLT consumption with details for subgroups of rural and urban women are scarce in SSA, especially in West Africa. However, 3.3\% of women and $4.7 \%$ of rural residents in Kenya were reported to be SLT users [21], as were $2.8 \%$ of women in Uganda [3]. Produced using a traditional technique, SLT is equivalent to a local psychoactive product and is widely available in rural Burkina Faso. There is no inventory concerning local psychoactive substances in Burkina Faso, and SLT seemed to be among the favourites of rural Burkinabé women, along with the roots of Sarcocephalus latifolius (a plant that provides synthetic tramadol), or non-medical tramadol, in Cameroon [22, 23] and khat/miraa in rural Kenya [24, 25].

\section{Co-use of alcohol}

Current SLT users were also frequently current alcohol users $(\mathrm{aOR}=2.80 ; 95 \% \mathrm{CI}: 2.06-3.80)$, as has been reported for women in Cambodia $(\mathrm{aOR}=1.49$; $95 \% \mathrm{CI}$ : $1.12-1.98)$ [26] and in Kenya $(\mathrm{aOR}=2.58 ; p=0.001$ for 
those with alcohol experience; $\mathrm{aOR}=4.84 ; p=0.007$ for episodic binge drinkers) [21]. SLT and alcohol are both psychoactive substances containing nicotine and ethanol molecules, respectively [27], and their synergistic interactive effects potentiate physical and psychological pleasure [28]. Therefore, polyconsumption of both tobacco and alcohol was not surprising [29]. Unfortunately, the use of tobacco and alcohol are considered major cardiovascular risk factors. Drinking alcohol is known to increase both HDL-C and total cholesterol concentrations [30], and the concurrent use of tobacco and alcohol enhances these increases [31]. Although the mean HDL cholesterol and total cholesterol values were not higher in SLT users than in nonusers, the mean total cholesterol value was significantly higher in concurrent current SLT and alcohol users than in nonusers (Table 2).

\section{Blood pressure and SLT use}

SLT use was associated with increases in SBP $(\mathrm{aOR}=$ 1.01; $p<0.05)$ and differential blood pressure $(\mathrm{aOR}=$ $1.01 ; p<0.05$ ) (Table 3). Substantial nicotine is absorbed from SLT products [14]. The predominant cardiovascular effects of nicotine result from the activation of the sympathetic nervous system, which causes a hypertensive effect [32]; the increase in SBP in our sample $(\mathrm{aOR}=1.01 ; p<0.05)$ was consistent with this effect and was consistent with the findings of Onwuchekwa in rural Niger ( $\mathrm{aOR}=2.32 ; p<0.05$ among rural residents) [33]. Furthermore, age-related increases in SBP have been reported to be greater in women than men [34, 35]; thus, the increase in SBP was more perceptible in our sample of women than it might have been in a sample of both men and women. However, we observed a decrease in DBP with age $(0.97 ; p<0.01)$ (Table 3$)$ in SLT users. We should note that there was an increase in DBP level with age from an average of $78.4( \pm 9.5) \mathrm{mmHg}$ at approximately 36 years of age to $83.1( \pm 11.8) \mathrm{mmHg}$ at 53 years and then a decrease to $73.4( \pm 10.1) \mathrm{mmHg}$ at 69 years of age [36]. An inverse association of DBP and age has been well established [36], and it may partly explain our finding. Nicotine interacts with central oestrogenic pathways [37], which may help explain the non-homogenous effects of nicotine on SBP and DBP. SLT is usually locally produced using a non-standardized processed, and tobacco is grown in different types of soils in which mineralogic contents (such as sodium) may affect blood pressure in users [38]. In addition, the use of pesticides in rural Burkina Faso may cause soil contamination by staining tobacco leaves [39], which has been implicated in BP increases [40]. The effects of chronic consumption of kola nuts on the cardiovascular system should be considered [41, 42]. Research showed that one in two adults used kola nuts in Burkina Faso [43], usually under similar conditions (i.e., dental health impairment conditions
[44]). Unspecified effects of interactions between SLT and kola nut products on BP may be possible. In short, cardiovascular disturbance in SLT users was evident in the substantial increase in differential blood pressure $(\mathrm{aOR}=1.01 ; p=0.041 ;$ Table 3$)$.

\section{Dental symptoms}

SLT use was associated with the presence of some dental symptoms $(\mathrm{aOR}=2.59 ; 95 \% \mathrm{CI}: 1.91-3.51)$. Cheema et al. reported an association with poor oral status $(\mathrm{aOR}=3.90$; 95\% CI: 1.75-8.69) in Qatar [4]. Users of this psychoactive substance (SLT) develop various expectancies for using it according to the different effects generated by its consumption depending on the context. Oro-dental pain and burning mouth syndrome are common in SSA countries, and poor oral health service utilization has been reported in these countries $[45,46]$. The nicotine delivered by SLT products increases sensory irritation [47], and because dental care is not available in rural Burkina Faso [44], rural women are likely to use SLT for the pain or discomfort associated with dental symptoms. Because chewing food might exacerbate dental pain, in the absence of treatment, those with dental symptoms use SLT to locally anaesthetize teeth or the oral cavity to be able to eat without pain. Such behaviour was noted in a supplemental qualitative study (interview) in three Ethiopian pastoral communities with a long tradition of SLT chewing [6]. Furthermore, psychoactive substance consumption resulting from addictive behaviours includes gestural rituals [48] that have been established over time. Tooth and periodontal damage was found to be common in SLT users [49], mainly female chewers [50], and the intention to use SLT for dental pain suppression could establish a vicious circle between dental symptoms and the repeated and inefficient application of SLT as treatment.

\section{Undernourishment}

The prevalence we found (16.0\%) was similar to the results reported in previous studies in Burkina Faso (14.8\% in rural and urban women in 2010 [51] and 19.9\% in 2016 [52]). The weighted prevalence of $14.8 \%$ was considered to be the greatest among the 33 SSA countries investigated, following the prevalences in Senegal (20.8\% in 2011) and Gambia (15.7\% in 2013) [51]. Moreover, the high prevalence of $31.0 \%$ found by Ramsey et al. in rural Burkina Faso was the highest among the three rural African areas involved in their study [53]. SLT use was associated with undernourishment $(\mathrm{aOR}=1.78 ; p<$ $0.01)$, as it was in rural Ghanaian women $(\mathrm{aOR}=2.78$; $p=0.002$ ) [54]. Tobacco delivers nicotine, which is an anti-appetite component [55]. There is low food availability in rural Burkina Faso [56], and hunger and an empty stomach generate discomfort. The belief that 
minimum food intake combined with SLT consumption helps allay hunger further exposes individuals to insufficient food intake. Similar habits were reported for addictions to tea and SLT among Malian Tuaregs living in Sahelian areas and suffering from hunger in a harsh climate [57].

\section{No significant impairment in the lipid profile or blood sugar among SLT users}

Lower HDL cholesterol and higher total cholesterol among smokers and tobacco chewers than among nonusers have been reported [58, 59]. However, the SLT users and nonusers in our current sample had identical mean values of HDL cholesterol and total cholesterol, and there was no significant risk of lipid profile impairment in SLT users (Tables $2 \& 3$ ). These results were not surprising in our context because SLT users were more frequently affected by undernourishment $(28.6 \%$ vs. $13.9 \%$ in nonusers; $p<0.001$ ) and not by overweight/ obesity (only $5.5 \%$ vs. $14.4 \%$ in nonusers; $p<0.001$; Table 2 ). The women in our study would frequently have moderate or insufficient amounts of fat in their bodies, including in blood vessels. Similarly, there was no association with increased blood sugar in users; their mean blood sugar was in fact significantly lower than that of nonusers $(3.8 \pm 1.5 \mathrm{mmol} / \mathrm{l}$ vs. $4.1 \pm 1.5$ in nonusers; $p<$ 0.05 ; Table 2). However, further investigations should consider the hypothesis of a positive association.

\section{Sociodemographic factor influences}

SLT use increased with age in our study (Table 3). It has previously been reported that elderly individuals have an increased number of cardiovascular risk factors [60] and that SSA countries under demographic and epidemiologic transitions have severely affected cardiovascular risk [61]. An additional modifiable factor, such as SLT use, should be avoided. Uneducated people were frequently exposed to SLT use (Table 3), which indicated that formal instruction, as well as public health education, focused on cardiovascular risk factors and SLT-related health consequences would be effective in reducing prevalence and risk [62].

\section{Limitations}

We used national data from the STEPS survey, which studied the prevalence of and knowledge of common risk factors for noncommunicable diseases. However, the sample size calculation was based on the prevalence of HBP. Data collection methods for dental symptoms were based only on self-reporting and did not include examinations by health professionals. Thus, self-reporting may have included incorrect statements and dental assessments.

\section{Conclusions}

The high prevalence of SLT use in women, unlike ST use, which is nearly non-existent in rural Burkina Faso, indicates a socially permissive attitude towards SLT use by females. The frequent occurrence of dental symptoms among SLT users reinforces the practice and reveals problematic access to oral health care in rural Burkina Faso. The frequent co-use of alcohol can result in the addictive practice known as polyconsumption (of these 2 psychoactive substances), which potentiates the psychological and physical effects and, unfortunately, includes adverse effects. Addictive habits may also include the expectation of immediate hunger suppression in an environment with low food availability. Thus, worsening undernourishment in SLT users might be connected to insufficient food intake resulting from the appetitesuppressing effects of the nicotine delivered by SLT used over the long term. The increases in SBP and differential blood pressure suggest serious cardiovascular concerns associated with SLT use. Furthermore, an overview of the chemical compounds and their levels in locally produced tobacco leaves should be given attention. The lack of increases in waist circumference and total cholesterol may be due to the severity of the undernourishment status of SLT users. Regarding ST use, National Public Health interventions are needed to reduce SLT use and its health-related concerns.

The efficacy of a brief dental office intervention for the general population of smokeless tobacco users was previously described [63]. Nevertheless, dentists and dental assistants should be more available in Burkina Faso. Interventions that could be undertaken may be to identify smokeless tobacco-related oral health problems, offer encouragement to set a quit date for cessation, provide tips on quitting, provide educational videos and encouragement to watch them, provide written educational materials and encouragement to read them, and provide phone call reminders regarding decisions to quit using smokeless tobacco [64].

\section{Abbreviations}

aOR: Adjusted odds ratios; BMI: Body mass index; Cl: Confidence interval; cOR: Crude odds ratio; DBP: Diastolic blood pressure; HBP: High blood pressure; HDL: High-density lipoprotein; mmHg: Millimetre per mercury; mmol/l: millimole per liter; NCDs: Non-communicable diseases; OR: Odds ratio; SBP: Systolic blood pressure; SLT: Smokeless tobacco; SSA: Sub-SaharanAfrican; ST: Smoked tobacco; STEPS: STEPwise approach to Surveillance; WHO: World Health Organization

\section{Acknowledgements}

The authors thank the Ministry of Health for providing them with the STEP survey database.

\section{Authors' contributions}

$J D, A N Z$ and $L N$ contributed to drafting the manuscript, JD and LN performed the statistical analysis, ANZ, JD, AO, LN, HT and AK provided the first interpretation of the results. PWS and SJBT reviewed the last version of the interpretation and discussion and AK and JD reviewed the last English version. All authors read and approved the final manuscript. 


\section{Funding}

None.

\section{Availability of data and materials}

The database of the STEPS survey used for this secondary analysis is available at the Ministry of Health of Burkina Faso. It can be requested directed to Dr. Brice Bicaba bicababrico78@gmail.com.

\section{Ethics approval and consent to participate}

The protocol of the STEPS survey was approved by the Ethics Committee for Health Research of the Ministry of Health (deliberation No: 2012-12092; December 05, 2012). Written informed consent was systematically obtained from each participant in the STEPS survey.

\section{Consent for publication}

Non applicable.

\section{Competing interests}

The authors declare that they have no competing interests.

\section{Author details}

'Public Health Department, Research Institute for Health Sciences, 399, Avenue de la Liberté, 01 BP 545, Bobo-Dioulasso 01, Burkina Faso. ² Public Health Department, Centre Muraz, Bobo-Dioulasso, Burkina Faso. ${ }^{3}$ Joseph Ki-Zerbo University, BP 5705, Ouagadougou 01, Burkina Faso. ${ }^{4}$ Institute of Environment and Agricultural Research (INERA/CNRST), rue Guisga, 04 BP 8645, Ouagadougou, Burkina Faso. ${ }^{5}$ Sourô Sanou University Hospital, 01 BP 676, Bobo-Dioulasso, Burkina Faso. ${ }^{6}$ Clinical Research Unit of Research Institute for Health Sciences Nanoro, 11 BP 218, Ouagadougou, Burkina Faso. ${ }^{7}$ Department of Psychiatry, Yalgado Ouédraogo University Hospital, Joseph Ki-Zerbo University, 01 BP 5705, Ouagadougou, Burkina Faso.

Received: 5 September 2019 Accepted: 14 April 2020 Published online: 28 April 2020

\section{References}

1. Sreeramareddy $C T$, Pradhan PM, Sin S. Prevalence, distribution, and social determinants of tobacco use in 30 sub-Saharan African countries. BMC Med. 2014;12:243

2. Agbor MA, Azodo CC, Tefouet TSM. Smokeless tobacco use, tooth loss and oral health issues among adults in Cameroon. Afr Health Sci. 2013;13:78590

3. Kabwama SN, Ndyanabangi S, Mutungi G, Wesonga R, Bahendeka SK, Guwatudde D. Tobacco use and associated factors among adults in Uganda: findings from a nationwide survey. Tob Induc Dis. 2016:14:27.

4. Cheema S, Maisonneuve P, Al-Thani MH, Al-Thani AAM, Abraham A, AlMannai GA, et al. Oral health behavior and factors associated with poor oral status in Qatar: results from a national health survey. J Public Health Dent. 2017:77:308-16

5. Somatunga LC, Sinha DN, Sumanasekera P, Galapatti K, Rinchen S, Kahandaliyanage A, et al. Smokeless tobacco use in Sri Lanka. Indian J Cancer. 2012:49:357-63.

6. Etu ES, Gemeda DH, Hussen MA. Prevalence and factors that influence smokeless tobacco use among adults in pastoralist communities of Borena zone, Ethiopia: mixed method study. Tob Induc Dis. 2017;15:1

7. Bhisey RA. Chemistry and toxicology of smokeless tobacco. Indian J Cancer. 2012;49:364-72.

8. Benowitz NL. Nicotine and smokeless tobacco. CA Cancer J Clin. 1988:38: 244-7.

9. Idris AM, Nair J, Ohshima H, Friesen M, Brouet I, Faustman EM, et al. Unusually high levels of carcinogenic tobacco-specific nitrosamines in Sudan snuff (toombak). Carcinogenesis. 1991;12:1115-8.

10. Chang MJW, Ko CY, Lin RF, Hsieh LL. Biological monitoring of environment exposure to safrole and the Taiwanese betel quid chewing. Arch Environ Contam Toxicol. 2002:43:0432-7.

11. Critchley JA, Unal B. Health effects associated with smokeless tobacco: a systematic review. Thorax. 2003:58:435-43.

12. Awan KH, Patil S. Association of smokeless tobacco with oral cancer evidence from the south Asian studies: a systematic review. J Coll Physicians Surg--Pak JCPSP. 2016;26:775-80.
13. Nonterah EA, Debpuur C, Agongo G, Amenga-Etego L, Crowther NJ, Ramsay M, et al. Socio-demographic and behavioural determinants of body mass index among an adult population in rural northern Ghana: the AWIgen study. Glob Health Action. 2018;11:1467588.

14. Benowitz NL, Porchet $H$, Sheiner L, Jacob P. Nicotine absorption and cardiovascular effects with smokeless tobacco use: comparison with cigarettes and nicotine gum. Clin Pharmacol Ther. 1988;44:23-8.

15. Baig S, Rubab Z, Farooq W. Molecular pathogenesis of chewable tobacco. J Coll Physicians Surg--Pak JCPSP. 2018;28:381-5.

16. Gupta R, Gupta S, Sharma S, Sinha DN, Mehrotra R. Risk of coronary heart disease among smokeless tobacco users: results of systematic review and meta-analysis of global data. Nicotine Tob Res Off J Soc Res Nicotine Tob. 2019:21:25-31

17. Bonita R, Winkelmann R, Douglas KA, de Courten M. The WHO stepwise approach to surveillance (Steps) of non-communicable disease risk factors. In: McQueen DV, Puska P, editors. Global behavioral risk factor surveillance. Boston: Springer US; 2003. p. 9-22. https://doi.org/10.1007/978-1-4615-0071$1 \_3$.

18. Soubeiga JK, Millogo T, Bicaba BW, Doulougou B, Kouanda S. Prevalence and factors associated with hypertension in Burkina Faso: a countrywide cross-sectional study. BMC Public Health. 2017:17:64

19. Millogo T, Bicaba BW, Soubeiga JK, Dabiré E, Médah I, Kouanda S. Diabetes and abnormal glucose regulation in the adult population of Burkina Faso: prevalence and predictors. BMC Public Health. 2018;18:350.

20. Araújo C, Silva-Matos C, Damasceno A, Gouveia ML, Azevedo A, Lunet N. Manufactured and hand-rolled cigarettes and smokeless tobacco consumption in Mozambique: regional differences at early stages of the tobacco epidemic. Drug Alcohol Depend. 2011;119:e58-65.

21. Ngaruiya C, Abubakar H, Kiptui D, Kendagor A, Ntakuka MW, Nyakundi $P$, et al. Tobacco use and its determinants in the 2015 Kenya WHO STEPS survey. BMC Public Health. 2018;18:1223.

22. Kusari S, Tatsimo SJN, Zühlke S, Talontsi FM, Kouam SF, Spiteller M. Tramadol--a true natural product? Angew Chem Int Ed Eng. 2014;53:12073-

23. Amadou I. Usages du Tramadol à des fins non médicales par les moto-taxi de la ville de Garoua. 2014. https://www.hsd-fmsb.org/index.php/hsd/thesis/ view/185. Accessed 3 Mar 2020.

24. Otieno AO, Ofulla AVO. Drug abuse in Kisumu town western Kenya. Afr J Food Agric Nutr Dev. 2009;9 https://www.ajol.info/index.php/ajfand/article/ view/43010. Accessed 3 Mar 2020.

25. Mekuriaw B, Belayneh Z, Yitayih Y. Magnitude of Khat use and associated factors among women attending antenatal care in Gedeo zone health centers, southern Ethiopia: a facility based cross sectional study. BMC Public Health. 2020;20:110.

26. Banta JE, Addison A, Job JS, Yel D, Kheam T, Singh PN. Patterns of alcohol and tobacco use in Cambodia. Asia Pac J Public Health. 2012. https://doi. org/10.1177/1010539512464649.

27. Lajtha A, Sershen $\mathrm{H}$. Nicotine: alcohol reward interactions. Neurochem Res. 2010:35:1248-58.

28. Boden MT, Heinz AJ, Kashdan TB. Pleasure as an overlooked target of substance use disorder research and treatment. Curr Drug Abuse Rev. 2016; 9:113-25

29. Klenowski PM, Tapper AR. Molecular, neuronal, and behavioral effects of ethanol and nicotine interactions. Handb Exp Pharmacol. 2018;248:187-212.

30. Whitehead TP, Robinson D, Allaway SL. The effects of cigarette smoking and alcohol consumption on blood lipids: a dose-related study on men. Ann Clin Biochem. 1996:33(Pt 2):99-106.

31. Rosoff DB, Charlet K, Jung J, Lee J, Muench C, Luo A, et al. Association of high-intensity binge drinking with lipid and liver function enzyme levels. JAMA Netw Open. 2019;2:e195844.

32. Donny EC, Caggiula AR, Sweitzer M, Chaudhri N, Gharib M, Sved AF. Selfadministered and yoked nicotine produce robust increases in blood pressure and changes in heart rate with modest effects of behavioral contingency in rats. Pharmacol Biochem Behav. 2011:99:459-67.

33. Onwuchekwa AC, Mezie-Okoye MM, Babatunde S. Prevalence of hypertension in Kegbara-dere, a rural community in the Niger Delta region. Nigeria Ethn Dis. 2012;22:340-6

34. Wojciechowska W, Stolarz-Skrzypek K, Tikhonoff V, Richart T, Seidlerová J, Cwynar M, et al. Age dependency of central and peripheral systolic blood pressures: cross-sectional and longitudinal observations in European populations. Blood Press. 2012;21:58-68. 
35. Li Y, Staessen JA, Sheng C-S, Huang Q-F, O'Rourke M, Wang J-G. Age dependency of peripheral and central systolic blood pressures: crosssectional and longitudinal observations in a Chinese population. Hypertens Res Off J Jpn Soc Hypertens. 2012;35:115-22.

36. Lane CA, Barnes J, Nicholas JM, Sudre CH, Cash DM, Parker TD, et al. Associations between blood pressure across adulthood and late-life brain structure and pathology in the neuroscience substudy of the 1946 British birth cohort (insight 46): an epidemiological study. Lancet Neurol. 2019;18: 942-52.

37. El-Mas MM, Fouda MA, El-Gowilly SM, Saad El. Central estrogenic pathways protect against the depressant action of acute nicotine on reflex tachycardia in female rats. Toxicol Appl Pharmacol. 2012;258:410-7.

38. Krogh L. Soil fertility variability and constraints on village scale transects in northern Burkina Faso. Arid Soil Res Rehabil. 1999;13:17-38.

39. Chen X, Zhang F, Yao H, Wang J, Qi D, Guo Y. Analyzing multiple pesticides in tobacco leaf using gas chromatography with quadrupole time-of-flight mass spectrometry. J Sep Sci. 2018;41:1983-9.

40. Park SK, Son HK, Lee SK, Kang JH, Chang YS, Jacobs DR, et al. Relationship between serum concentrations of organochlorine pesticides and metabolic syndrome among non-diabetic adults. J Prev Med Public Health. 2010;43:1-8.

41. Agatha M, Breckenridge C, Soyemi EA. Some preliminary observations on the effects of kola nut on the cardiovascular system. Niger Med J J Niger Med Assoc. 1978;8:501-5.

42. Osim EE, Udia PM. Effects of consuming a Kola Nut (Cola Nitida) diet on mean arterial pressure in rats. Int J Pharmacogn. 1993;31:193-7.

43. Abellard J, Decroix B, Kerebel LM. Epidemiologic survey of orodental health in Fada N'Gourma (Burkina Faso). Bull Group Int Rech Sci Stomatol Odontol. 1989;32:31-8.

44. Tapsoba H, Deschamps JP. Oral-dental health in the national health system of Burkina Faso. Sante Montrouge Fr. 1997;7:317-21.

45. Olusile AO, Adeniyi AA, Orebanjo O. Self-rated oral health status, oral health service utilization, and oral hygiene practices among adult Nigerians. BMC Oral Health. 2014;14:140.

46. Msyamboza KP, Phale E, Namalika JM, Mwase Y, Samonte GC, Kajirime D, et al. Magnitude of dental caries, missing and filled teeth in Malawi: National Oral Health Survey. BMC Oral Health. 2016;16:29.

47. Kobal G, Heynekamp J, Langston TB, Reeh P, Mishra MK, Flora JW. Inhibition of sensory irritation during consumption of non-smokeable tobacco products. 2018. https://patents.google.com/patent/US10117453B2/en. Accessed 25 May 2019.

48. Gray MT. Habits, rituals, and addiction: an inquiry into substance abuse in older persons. Nurs Philos Int J Healthc Prof. 2014;15:138-51.

49. Burgan SW. The role of tobacco use in periodontal diseases: a literature review. Gen Dent. 1997;45:449-60 quiz 469-70.

50. Giovannoni ML, Valdivia-Gandur I, Lozano de Luaces V, Varela Véliz H, Balasubbaiah Y, Chimenos-Küstner E. Betel and tobacco chewing habit and its relation to risk factors for periodontal disease. Oral Dis. 2018;24:829-39.

51. Yaya S, Ekholuenetale M, Bishwajit G. Differentials in prevalence and correlates of metabolic risk factors of non-communicable diseases among women in sub-Saharan Africa: evidence from 33 countries. BMC Public Health. 2018;18:1168.

52. Olney DK, Bliznashka L, Pedehombga A, Dillon A, Ruel MT, Heckert J. A 2year integrated agriculture and nutrition program targeted to mothers of young children in Burkina Faso reduces underweight among mothers and increases their empowerment: a cluster-randomized controlled trial. J Nutr. 2016;146:1109-17.

53. Ramsay M, Crowther NJ, Agongo G, Ali SA, Asiki G, Boua RP, et al. Regional and sex-specific variation in BMl distribution in four sub-Saharan African countries: the H3Africa AWl-gen study. Glob Health Action. 2018;11:1556561.

54. Blankson B, Hall A. The anthropometric status of elderly women in rural Ghana and factors associated with low body mass index. J Nutr Health Aging. 2012;16:881-6.

55. Pilhatsch M, Scheuing $H$, Kroemer N, Kobiella A, Bidlingmaier M, Farger G, et al. Nicotine administration in healthy non-smokers reduces appetite but does not alter plasma ghrelin. Hum Psychopharmacol. 2014;29:384-7.

56. Frongillo EA, Nanama S. Development and validation of an experiencebased measure of household food insecurity within and across seasons in northern Burkina Faso. J Nutr. 2006;136:1409S-19S.

57. Hureiki J, Laqueille $X$. The Tuaregs addiction to tea, to smokeless tobacco and to milk: ethnological and clinical approach. L'Encephale. 2003;29:42-8.
58. Khurana M, Sharma D, Khandelwal PD. Lipid profile in smokers and tobacco chewers--a comparative study. J Assoc Physicians India. 2000;48:895-7.

59. Rao Ch S, Subash YE. The effect of chronic tobacco smoking and chewing on the lipid profile. J Clin Diagn Res JCDR. 2013;7:31-4.

60. Phaswana-Mafuya N, Peltzer K, Chirinda W, Musekiwa A, Kose Z. Sociodemographic predictors of multiple non-communicable disease risk factors among older adults in South Africa. Glob Health Action. 2013;6: 20680.

61. Smith SM, Mensah GA. Population aging and implications for epidemic cardiovascular disease in sub-Saharan Africa. Ethn Dis. 2003;13(2 Suppl 2): S77-80.

62. Crouch R, Wilson A, Newbury J. A systematic review of the effectiveness of primary health education or intervention programs in improving rural women's knowledge of heart disease risk factors and changing lifestyle behaviours. Int J Evid Based Healthc. 2011;9:236-45.

63. Stevens VJ, Severson H, Lichtenstein E, Little SJ, Leben J. Making the most of a teachable moment: a smokeless-tobacco cessation intervention in the dental office. Am J Public Health. 1995:85:231-5.

64. Andrews JA, Severson HH, Lichtenstein E, Gordon JS, Barckley MF. Evaluation of a dental office tobacco cessation program: effects on smokeless tobacco use. Ann Behav Med Publ Soc Behav Med. 1999;21:4853.

\section{Publisher's Note}

Springer Nature remains neutral with regard to jurisdictional claims in published maps and institutional affiliations.
Ready to submit your research? Choose BMC and benefit from:

- fast, convenient online submission

- thorough peer review by experienced researchers in your field

- rapid publication on acceptance

- support for research data, including large and complex data types

- gold Open Access which fosters wider collaboration and increased citations

- maximum visibility for your research: over $100 \mathrm{M}$ website views per year

At $\mathrm{BMC}$, research is always in progress.

Learn more biomedcentral.com/submissions 